Artykuly / Articles

\author{
Игорь ХАебников \\ ORCID: 0000-0002-2695-5580 \\ igorkhlebnikov79@gmail.com \\ Карагандинский университет им. Е.А. Букетова \\ Исторический факультет \\ Казахстан \\ Натапья Донецкая \\ ORCID: 0000-0003-4725-5740 \\ ndonetskaja@mail.ru
}

Карагандинский университет им. Е.А. Букетова Фимософско-психологический факультет

Казахстан

\title{
На пути к общественному развитию. Информационные техномогии и ресурсы в высшем образовании ${ }^{1}$
}

On the Way to Social Development. Information Technologies
and Resources in Higher Education

Na drodze rozwoju społecznego. Technologie i zasoby informacyjne w szkolnictwie wyższym

DOI: $10.34739 /$ doc.2021.18.04

\begin{abstract}
Аннотация: Эволюция социальных отношений на современном этапе требует от преподавателей, работающих в сфере высшего образования развитьх навыков использования информационных ресурсов и цифровых технологий. От интенсивности коммуникаций в информационной сфере зависит эффективность не только процесса обучения в университете, но и в значительной степени, вторичной социализации молодежи. В статье рассматривается проблема использования преподавателями казахстанских университетов (на примере Карагандинского региона) информационных ресурсов и цифровых технологий. Статья подготовлена на основе данных социологического исследования (анкетного опроса), проведенного в университетах Карагандинского региона Казахстана. Цель проведенного

1 Статья подготовлена в рамках научного проекта по гранту АР08052518 "Формирование информационной культуры казахстанской молодежи как фактор роста интеммектуального потенциала общества" (2020-2022 гг.), Комитет науки Министерства образования и науки Республики Казахстан.
\end{abstract}


исследования состояла в анализе эффективности использования информационных технологий и ресурсов в процессе обучения в университетах и выработке практических рекомендаций для повышения эфффективности обучения. По результатам проведенного исследования было установлено, что на развитие информационно-коммуникационной сферы в университетах оказывают влияние "объективные" и "субъективные" факторы. Первые связаны с недостатками в техническом обеспечении учебного процесса, вторые - с недостаточной осведомленностью некоторых преподавателей о современных Интернет-ресурсах в своей профессиональной области. Обозначенные проблемы могут быть преодомены при помощи комплекса мероприятий, направленных на повышение информированности преподавателей об имеющихся информационных ресурсах, увеличение скорости Интернет-соединения и общей технической оснащенности университетов.

К^ючевые слова: общественное развитие, информационные ресурсы, информационные технологии, телекоммуникационные технологии, высшее образование, информационные ресурсы

Abstract: The evolution of social relations at the present stage requires teachers to work in the field of higher education to develop skills in using information resources and digital technologies. The intensity of communication in the information sphere determines the effectiveness of not only the learning process at the university, but also to a large extent, the secondary socialization of young people. The article deals with the problem of using information resources and digital technologies by teachers of Kazakh universities (on the example of the Karaganda region). The article is based on the data of a sociological survey (questionnaire survey) conducted at the universities of the Karaganda region of Kazakhstan. The purpose of the study was to analyze the effectiveness of the use of information technologies and resources in the process of studying at universities and to develop practical recommendations to improve the effectiveness of training. According to the results of the study, it has been found out that the development of the information and communication sphere in universities is influenced by "objective" and "subjective" factors. The first ones are connected with shortcomings in the technical support of the educational process, the second ones- with some teachers' lack of awareness of the modern Internet resources in their professional field. The identified problems can be overcome with the help of measures aimed at increasing teachers' awareness of available information resources, increasing the speed of the Internet connection and general technical equipment of universities.

Keywords: social development, information resources, information technologies, telecommunication technologies, higher education, information resources

Abstrakt: Ewolucja stosunków społecznych w nowoczesnych warunkach wy-
maga od nauczycieli korzystania $z$ zasobów informacyjnych i technologii cyfro-
wych. Efektywność nie tylko procesu kształcenia na uczelni, ale także stopień
wtórnej socjalizacji młodzieży zależy od intensywności komunikacji w sferze
informacyjnej. Artykuł dotyczy problemu wykorzystania zasobów i technologii
cyfrowych przez wykładowców kazachskich uniwersytetów (na przykładzie re-
gionu Karaganda). Artykuł został przygotowany na podstawie danych z badania
socjologicznego ( $\mathrm{z}$ wykorzystaniem kwestionariusza ankiety) przeprowadzonego
w uniwersytetach regionu karagandyjskiego w Kazachstanie. Celem badania 
efektywności wykorzystania technologii i zasobów informatycznych w procesie kształcenia na uczelniach było przedstawienie praktycznych rekomendacji w celu poprawy jego efektywności. Na podstawie wyników badań stwierdzono, że na rozwój sfery informacyjno-komunikacyjnej na uczelniach wpływaja czynniki "obiektywne” i „subiektywne”. Pierwsze wiążą się $z$ niedociagnięciami $\mathrm{w}$ sferze technicznej procesu edukacyjnego, drugie $-z$ brakiem świadomości niektórych wykładowców na temat nowoczesnych zasobów Internetu w swojej dziedzinie zawodowej. Zidentyfikowane problemy można przezwyciężyć za pomoca działań, których celem jest zwiększenie szybkości informowania wykładowców o wykorzystaniu zasobów informacyjnych, zwiększenie szybkości łącza internetowego oraz ogólnego wyposażenia technicznego uniwersytetów.

Słowa kluczowe: rozwój społeczny, zasoby informacyjne, technologie informacyjne, technologie telekomunikacyjne, szkolnictwo wyższe, zasoby informacyjne

Вхождение современного общества в цифровую эпоху обуславливает необходимость формирования и развития информационной культуры. От развитости навыков взаимодействия в информационном поле зависит эффектив-ность процесса социализации и успешность адаптации $\mathrm{k}$ ускоряющимся процессам эволюции общества. Развитие современных компьютерных телекоммуникационных и информа-ционных систем привело к появлению новых технологий и средств обучения. Компьютерные технологии обеспечили возможность перехода на качественно иной уровень передачи информации и даже обусловили, по мнению некоторых авторов, формирование целого поколения "айдженеров", которому впервые стал практически повсеместно доступен Интернет ${ }^{2}$.

В мировой научной практике, пропорционально расширению информационной сферы, наблюдается возрастание исследовательского интереса к проблематике развития информационной культуры применительно к институту образования. Так, проводится изучение проблем онлайн участия подростков в интернет-пространстве, онлайн-самоидентификации молодежи, развития технологических навыков обучения и социализации ${ }^{3}$.

\footnotetext{
2 Д. Твенге, Поколение І. Почему поколение Интернета утратило бунтарский дух, стало более толерантньм, менее счастливым и абсолютно неготовым ко взрослой жизни, Москва 2019, с. 17.

3 C. Davies, R. Eynon, Teenagers and Technology, New York-London 2013.
} 
Анализируется практическая реализация прав человека в условиях цифровой эпохи, подчеркивается важность сети Интернет как инструмента расширения индивидуальной свободы, способствующего росту креативности при условии обеспечения равных возможностей в данной сфере ${ }^{4}$. Исследования в этом направлении обеспечивают фундамен-тальную основу дмя дальнейшего анализа, направленного на преодоление "цифрового разрыва" - существующего неравенства в информационной сфере, обусловленного как различными техническими возможностями поцьзователей сети, в особенности молодежи, так и существующими ограничениями со стороны государства.

Проводится изучение влияния социальных сетей по вовлечению широких слоев населения, вкцючая молодежь, В область мировой политики. Расширение возможностей современных технических средств, повышение интерактивной составляющей интернет-сайтов, объективно способствуют повышению прозрачности политической сферы и доступности информации, касающейся мировых политических процессов. Полученные результаты имююстрируют изменения, происходящие в области сетевой социализации, влияющие на изменение способов социальной коммуникации в медиасфере, качественно изменяющие процесс коммуникации в современном мире 5 .

Важным направлением анализа в отмеченном контексте представляется изучение вцияния внедрения цифровых ресурсов на трансформацию образовательной и научной деятельности, в особенности в области социогуманитарного знания. Делается вывод о неизбежной цифровизации области гуманитарных наук, внедрении принципиально новых обучающих и аналитических инструментов, возникших благодаря расширению цифровой составляющей информационной кумьтуры ${ }^{6}$.

От развитости навыков взаимодействия в информационном поле в настоящее время зависит эффективность процесса социализации и успешность адаптации молодого

\footnotetext{
${ }^{4}$ A. Peacock, Human Rights and the Digital Divide, New York 2019.

5 L.J. Shepherd, C. Hamilton, Understanding Popular Culture and World Politics in the Digital Age, New York 2019.

6 M. Dodd, N. Kalra, Exploring Digital Humanities in India. Pedagogies, Practices, and Institutional Possibilities, New York 2020.
} 
поколения к ускоряющимся процессам эволюции общества. В информа-ционное поле постепенно смещается все больше "традиционных" видов деятельности; в настоящее время онлайн образование и удаленная работа, интернет вещей, онлайн шоппинг, интернет-моббинг стали необходимой частью жизни современного человека. В значительной степени ускорила процесс расширения информационного поля ситуация, связанная с пандемией COVID-19, вследствие которой произошли значительные изменения в основных сферах жизни общества, направленные на интенсификацию онлайн интеракции, как наиболее безопасной с точки зрения предотвращения распространения коронавирусной инфекции. Соответственно, наблюдается процесс трансформации ценностно-нормативной сферы, изменяется образ жизни и образ действий современного человека. Молодежь, как наиболее динамичная часть социума, находится на острие данных процессов. С одной стороны, она интенсивнее, по сравнению с представителями старших поколений, воспринимает происходящие изменения, с другой, молодые мюди зачастую затрудняются рационально определить свои информационные потребности, что открывает возможности для манипуляций, способствует увеличению социальной напряженности и конфмиктов.

Кроме того, мультимедиа позволяют создавать средства обучения с широкими интерактивными возможностями. На сегодня стала реальностью передача компьютерной программе части функций, выполняемых преподавателем в ходе учебного процесса 7 . Соответственно, роль информационных технологий и ресурсов в образовании (в первую очередь, высшем) постоянно возрастает. Их внедрение в образовательную систему на уровне каждого учебного заведения играет важную роль в деле ее преобразования и международной интеграции. Таковы основания, обусловившие проведение социологического исследования, результатом которого явицся анализ эффективности использования преподавателями высших учебных заведений

\footnotetext{
7 Е.И. Выштынецкий, А.О. Кривошеев, Вопросы применения информаиионных технологий в сфере образования и обучения, „Информационные технологии” 1998, № 2, с. 20.
} 
информационных технологий и ресурсов по следующим направ ениям:

- виды используемых информационных технологий;

- интенсивность их применения в учебном процессе;

- проблемный аспект реализации информационных технологий.

Цель исследования - на основе данных социологического исследования проанализировать эффективность использования информационных технологий и ресурсов в учебном процессе вузов и разработать практические рекомендации с целью совершенствования организации образовательного процесса. Объект исследования - преподаватели 5 вузов Карагандинской области, которые выступили в качестве источника информации о видах используемых информационных технологий и интенсивности их применения в процессе обучения. Предмет исследования - эффективность использования информационных технологий и ресурсов в учебном процессе и факторы, оказывающие на нее прямое или косвенное воздействие.

Основная гипотеза исследования заключалась в следующем: предварительный анализ проблемной ситуации, а также данные социологических исследований, проводившихся по сходной проблематике, позволили сделать предположение, что эффективность использования информационных технологий непосредственным образом связана с интенсивностью их применения, а также соответствующей мотивацией субъектов учебного процесса. В соответствии с основной гипотезой специальные блоки вопросов анкеты были нацелены на выявление интенсивности использования преподавателями в процессе обучения информационных ресурсов, а также их оценок эффективности различных видов данных ресурсов. Основная гипотеза не рассматривала другие причины, способные влиять на состояние отмеченной проблемы, в связи с чем потребовалось сформулировать гипотезу-следствие: "Социально-демографические характеристики респондентов не явцяются факторами, оказывающими воздействие на эффективность использования информационных технологий на статистически значимом уровне».

Проверка сформулированных гипотез потребовала решения следующих задач. Дия основной гипотезы - выявить характер 
влияния на эффективность использования в учебном процессе информационных технологий и ресурсов интенсивности их применения и удовлетворенности данными технологиями. Для проверки гипотезы-следствия - выявить характер влияния на указанную проблему:

1) социально-демографических характеристик преподавателей;

2) домжности;

3) профессионамьной специамизации.

При проведении полевого этапа реализована простая случайная бесповторная выборка. Учитывая, что объем генеральной совокупности (общая численность преподавателей вузов Карагандинской области), согласно данным Комитета по статистике Министерства национальной экономики Республики Казахстан составиц 3067 чемовек $^{8}$, объем выборочной совокупности рассчитан по формуле:

$$
\begin{gathered}
n=\frac{Z^{2} S^{2} N}{\Delta N+Z^{2} S^{2}} \\
\mathrm{n}=(1,962 * 0,25 * 3067):(0,052 * 3067+1,962 * 0,25)=341 \text { чел. }
\end{gathered}
$$

Данный объем выборки гарантировал статистически значимые результаты. Сбор первичной социологической информации осуществлен посредством анкетного опроса. Доля респондентов, имеющих ученую степень доктора наук, составила $3,2 \%$, кандидата наук - 25,9\%. Разработка и эксплуатация информационных образовательных технологий и ресурсов неразрывно связана с оценкой эффективности их применения в образовательном процессе. Информационные ресурсы могут использоваться в учебном процессе в различных пропорциях, как в очной, так и в заочной формах получения образования, что способствует реализации полного дидактического цикла обучения.

\footnotetext{
8 Комитет по статистике Министерства национальной экономики Республики Казахстан, Статистика образования по Карагандинской области, https://old.stat.gov.kz/faces/karaganda/regPublications/reg_OperData/reg_Publi c23?_afrLoop=6202346465335248\#\%40\%3F_afrLoop\%3D6202346465335248\% 2 6_adf.ctrl-state\%3Dsygfz8ypw_77 (дата доступа: 15.12.2020).
} 
Проведенное исследование позволило выявить интенсивность использования в процессе преподавания основных видов информационных ресурсов. К их числу относятся: периодические интернет-издания; интернет-сайты образовательного или научного профиля; электронные библиотеки сети Интернет; эмектронная библиотека вуза; медиатека вуза; мокальная сеть вуза. Полученные данные свидетельствуют, что наиболее интенсивно задействованы ресурсы электронных библиотек вузов (постоянно обращаются к ее услугам 35,4\% опрошенных преподавателей и 47,4\% - периодически) и Интернет-изданий (35,3\% - обращаются постоянно, 56,8\% - периодически). Также популярны ресурсы мокальных сетей университетов (32,3\% обращаются постоянно, 50,5\% - периодически) и интернетбиблиотек (31,7\% - обращаются постоянно, 50,5\% - периодически), сайты научной и образовательной направленности (31,3\% - обращаются постоянно, 59,4\% - периодически), медиатеки университетов (21,3\% - обращаются постоянно, 56,8\% - периодически).

При этом на использование электронных курсов мекций, собранных в библиотеках вузов, ориентируют студентов, по их собственному признанию, 72,3\% опрошенных преподавателей. Рекомендуют студентам учебные и научные интернет-ресурсы $89,5 \%$ респондентов. Однако на просьбу указать адреса тематических сайтов дали четкий ответ томько 18,9\% преподавателей. Остальные ограничились адресами так называемых "Интернет-поисковиков", которые используются дия поиска информации самого разцичного характера - google.com, yandex.ru, и т.п.

Тем не менее, бомьшинство респондентов (82,8\%) полагают, что студенты осведомлены об информационных технологиях и ресурсах, имеющихся в их вузах, и в основной своей массе вмадеют навыками работы с ними $(88,5 \%)$. Информационные технологии на своих занятиях применяют 61,6\% опрошенных, из которых 26,8\% используют наглядные материалы, представленные в программе Power Point; 18,4\% - электронные учебники; 16,4\% - специализированные обучающие компью-терные программы. Основные трудности, связанные с применением данных технологий, обусловлены, по мнению респондентов, нехваткой оборудованных компьютерами аудиторий $(19,6 \%)$, 
отсутствием качественного интернет-соединения в сети вуза $(16,3 \%)$, устаревшим оборудованием (16,3\%), «недостатком времени" (3,1\%). В процессе проведения занятий также задействованы мультимедийные мекционные залы и тьюторские классы. Используют их соответственно $61,0 \%$ и $47,9 \%$ преподавателей.

Таким образом, свыше 80\% опрошенных преподавателей заявики об использовании на занятиях и в процессе подготовки к ним информационных и телекоммуникационных технологий. При этом домю систематически работающих с данными ресурсами следует признать значительной - более 60\% опрошенных. Об этом свидетельствует число респондентов, указавших Интернет-сайты, к которым они обращались в процессе работы, а также количество применяющих на занятиях информационные и телекоммуникационные технологии $(61,6 \%)$.

Эффективность реализации информационных технологий напрямую связана с удовцетворенностью участников учебного процесса их дидактическими возможностями. Давая общую оценку указанному параметру, 92,8\% опрошенных отметили, что использование информационных технологий способно существенно повысить эффективность учебного процесса. Также респондентам было предложено оценить эффективность различных видов информационных ресурсов (Рисунок 1). Как видно из представценного распредемения, в наибольшей степени соответствуют информационным потребностям преподавателей периодические интернет-издания и электронные библиотеки (в т.ч. имеющиеся в их учебных заведениях).

Следует также отметить, что эффективность реализации информационных технологий снижает отсутствие мичного компьютера, подкцюченного к сети Интернет, у некоторого количества $(9,7 \%)$ опрошенных преподавателей (впрочем, они имеют возможность пользоваться компьютером на работе). При этом компьютеры используются респондентами для разцичных задач: набора и распечатки текстового материала (85,4\%), для выхода в Интернет $(65,6 \%)$, дмя чтения научной и учебной митературы (49,0\%), для работы со специализированными, например, статистическим, программами (46,9\%), "для развлечений" (20,8\%), дмя чтения художественной митературы (9,4\%). 
Рисунок 1. Оценка эффективности различных видов информационных ресурсов (в процентах от общего количества опрошенных)

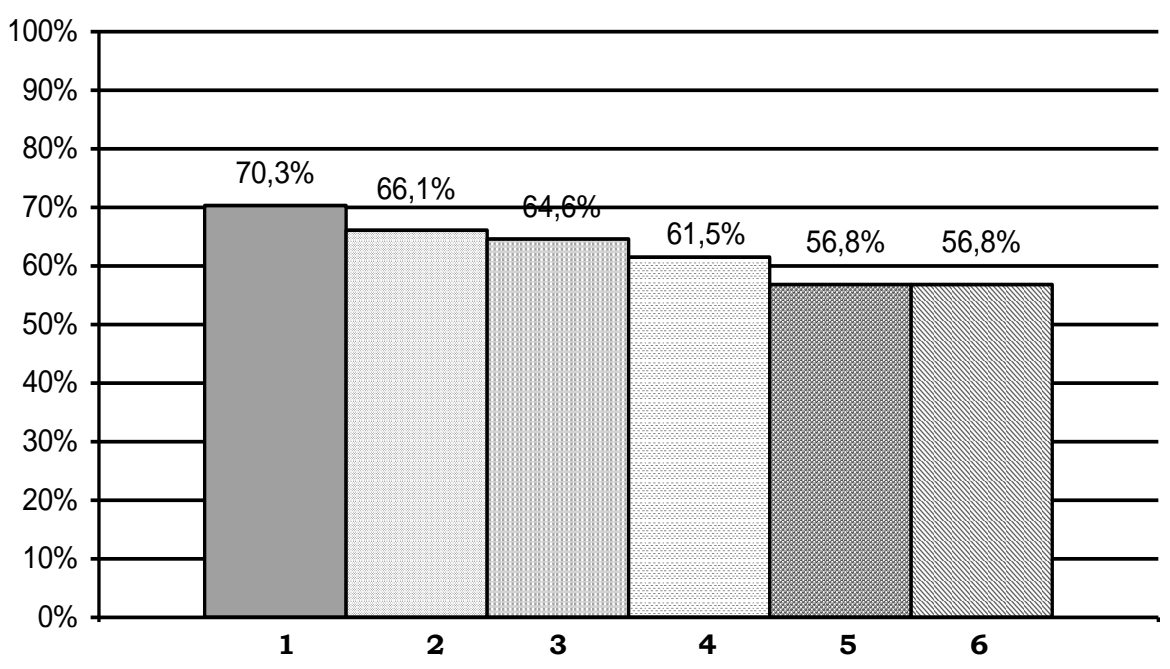

\section{Примечание:}

1 - периодические электронные издания (в сети Интернет)

2 - эмектронные библиотеки в сети Интернет

3 - эмектронная библиотека вуза
4 - Интернет-сайты размичных организаций научного и (или) образовательного профиля

5 - медиатека вуза

6 - мокальная сеть вуза

Обращает на себя внимание тот факт, что технические параметры компьютеров и другой оргтехники, имеющейся на рабочем месте, отвечает потребностям мишь 44,8\% преподавателей. Вместе с тем 62,5\% отмечают, что испытывают неудобства, связанные с отсутствием возможности тиражировать материалы, необходимые им при подготовке к занятиям. Респонденты также предложили ряд возможных мер, направленных на повышение эффективности информационного обеспечения учебного процесса:

- увеличить количество копировальных аппаратов (сканеров и копиров) в учебных корпусах вузов (62,5\%);

- увеличить скорость Интернет-соединения (14,6\%);

- повысить требования к компьютерной грамотности преподавателей и студентов (6,5\%).

Как следует из результатов анкетирования, эффективность информационных технологий оценивается респондентами достаточно высоко. Тем не менее, возможности использования 
преподавателями в учебном процессе информационных ресурсов ограничены в ряде случаев, незнанием соответствующих возможностей сети Интернет.

По приведенным выше результатам настоящего исследования, полученным в ходе опроса и обработки его данных, можно сдемать следующие выводы:

1. Большинство опрошенных преподавателей используют на занятиях и в процессе подготовки к ним разцичные информационные и телекоммуникационные технологии, причем домя систематически работающих с данными ресурсами является значитецьной.

2. Удовлетворенность преподавателей имеющимися в наличии информационными ресурсами находится на высоком уровне. При этом в наибольшей степени соответствуют информационным потребностям преподавателей периодические интернет-издания и эмектронные библиотеки.

3. По результатам исследования выделены проблемные области, связанные с практическим применением в учебном процессе информационных технологий:

- недостаточно высокая скорость Интернет-соединения (включая беспроводное) в учебных корпусах университета;

- недостаточно высокая осведомленность части преподавателей о современных Интернет-ресурсах в своей профессиональной области;

- недостаток копировально-множительной техники в учебных корпусах.

Решение обозначенных проблем потребует в дальнейшем реализации комплекса мероприятий, направленных на повышение информированности преподавателей об имеющихся информационных ресурсах, главным образом, сетевых; на увеличение скорости Интернет-соединения, прежде всего, беспроводного, в учебных корпусах вузов; на увеличение количества копировально-множительных аппаратов в вузах. 


\section{Бибмиография / References}

Davies C., Eynon R., Teenagers and Technology, New York-London 2013.

Dodd M., Kalra N., Exploring Digital Humanities in India. Pedagogies, Practices, and Institutional Possibilities, New York 2020.

Komitet po statistike Ministerstva nacional'noj èkonomiki Respubliki Kazahstan, Statistika obrazovaniâ po Karagandinskoj oblasti, https://old.stat.gov.kz/faces/karaganda/regPublications/reg_OperD ata/reg_Public23?_afrLoop=6202346465335248\#\%40\%3F_afrLoop\% 3D6202346465335248\%26_adf.ctrl-state\%3Dsygfz8ypw_77 (data dostupa: 15.12.2020). [Комитет по статистике Министерства национальной экономики Республики Казахстан, Статистика образования по Карагандинской области, https://old.stat.gov.kz/ faces/karaganda/regPublications/reg_OperData/reg_Public23?_afr Loop=6202346465335248\#\%40\%3F_afrLoop\%3D620234646533524 8\%26_adf.ctrl-state\%3Dsygfz8ypw_77 (дата доступа: 15.12.2020)].

Peacock A., Human Rights and the Digital Divide, New York 2019.

Shepherd L.J., Hamilton C., Understanding Popular Culture and World Politics in the Digital Age, New York 2019.

Tvenge D., Pokolenie I. Počemu pokolenie Interneta utratilo buntarskij duh, stalo bolee tolerantnym, menee sčastlivym $i$ absolûtno negotovym ko vzrosloj žizni, Moskva 2019. [Твенге Д., Поколение I. Почему поколение Интернета утратило бунтарский дух, стало более толерантным, менее счастливым и абсолютно неготовым ко взрослой жизни, Москва 2019].

Vyštyneckij E.I., Krivošeev A.O., Voprosy primeneniâ informacionnyh tehnologij v sfere obrazovaniâ i obučeniâ, „Informacionnye tehnologii”, 1998, № 2. [Выштынецкий Е.И., Кривошеев А.О., Вопросы применения информационных технологий в сфере образования и обучения, „Информационные технологии”, 1998, № 2]. 